\title{
"Double bind" in educational process as a factor of activization of students' clip way of thinking
}

\author{
Olga Efremova $^{1,{ }^{*}}$, Larisa Kobysheva ${ }^{1}$ and Svetlana Shalova ${ }^{1}$ \\ ${ }^{1}$ Taganrog Institute of A.P. Chekhov (Branch) of Rostov State University of Economics, \\ Taganrog 347936, Russia
}

\begin{abstract}
The article empirically substantiates the connection between "double bind", created in educational situation, with manifestation of negative aspects of the clip way of thinking among students. On the basis of scaling techniques and factor analysis the contradictory subconscious programmings of students in connection with "double bind" situation, caused by inconsistency of the requirements imposed to them, are characterized. Among such programmings is an attempt to simultaneously adapt to the declared requirements and actual expectations of teachers; supporting the teacher's position and demonstrating a different position; ignoring time-consuming work when understanding its necessity; the desire to fulfill the requirements of teachers while trying to minimize efforts in educational work. Some features of manifestation of students' clip way of thinking are highlighted: superficiality of information processing, areflexivity, simplification, linguistic minimalism, high speed of work with information at the expense of quality, stereotyped judgments and conclusions. A correlation between the intensity of "double bind" among students and the degree of manifestation of indicators of clip way of thinking is determined. The need to avoid inconsistency in pedagogical requirements to students, the importance of monitoring students' compliance with the requirements to exclude possibility of conflicting programmings that create "double bind" is emphasized.
\end{abstract}

\section{Introduction}

The phenomenon of "double bind" described by G. Bateson (1972), leading to communicative disorganization and mental disturbances, occurs not only in the situation of family education, but also in broad social communication and education (Mayer, 2012). The essence of "double bind" involves presentation to the subject the two mutually exclusive prescriptions, fulfillment of each being negatively sanctioned, and at the same time limiting the exit from the situation of choice, as well as excluding the possibility of discussing this dilemma with anyone. A situation is possible when conflicting prescriptions are directed by different individuals (Mayer, 2012). One of such dilemmas that a child faces with in a family is delegation by parents of communication and education functions to a computer, while prohibiting long-term use of it in order to avoid computer addiction. The consequences of active use of gadgets by children are such phenomena as "digital dementia" (Spitzer, 2008),

\footnotetext{
* Corresponding author: efrem.olg@yandex.ru
} 
autization (Babaeva, Voiskunsky, 2008), "clip way of thinking” (Chirkova, 2016). In vocational education at the "teacher - student" level of communication the situation of "double bind" is constantly reproduced. One of the consequences of this repeating situation is the formation of student's qualities, which, as noted by T.I. Chirkova (2016), are specific for clipping consciousness: instability and inconsistency of axiological formations, striving for recreation, individualism, decreased social activity, deviating behavior. This article empirically substantiates connection between "double bind" in the "teacher - student" communication system with the manifestation of students' clip way of thinking in the educational process.

\section{Materials and methods}

The article is based on Gregory Bateson's concept of "double bind" and psychological studies on the issues of "clip way of thinking" and "double bind" in the educational situation, carried out by modern Russian and foreign researchers. Methods used: phenomenological and problem analysis; scaling of the degree of effectiveness of "double bind" requirements and the degree of manifestation of "clip way of thinking" indicators, performed by students; correlation and factor analysis.

\section{Results}

As a result of the study it was observed that many students rated high some pairs of conflicting statements. One third of the respondents rated almost equally high (for example, 9 and 7, 7 and 8 points) such statements: "An academically successful student usually expresses his personal point of view on the issues discussed in the classroom"; "An academically successful student usually expresses in the classroom not his point of view, but the one suggested by the teacher". $38.9 \%$ of the respondents rated the following statements approximately equally: "Extracurricular activities should not distract a student from educational activities"; "It is important for a student to make a name in extracurricular activities, in that case there is no need to worry about academic outcomes. $40.7 \%$ of respondents rated high the following pair of statements: "In class one should not use a smartphone to look for the answers to teacher's questions"; "It's better to use a smartphone in class if you don't know the answer to teacher's question". More than half of the respondents (55.6\%) expressed a high degree of agreement with the following statements: "Information presented by a student in text and tabular form is perceived more clearly than visual (pictures, illustrations)", "Information presented by a student mainly in the form of pictures and illustrations, is perceived better than the text one". Despite the fact that some of the statements of each pair in logical terms do not completely contradict each other, in practice they express the opposite attitudes of the teacher and are able to disorientate student. As to other pairs of teachers' conflicting attitudes, some students put ratings close to the middle of the scale (for example, 5 and 6 points, 5 and 5, 4 and 6). Other students showed opposite ratings (for example, 7 and 1 points), sometimes there was a partial discrepancy between ratings (for example, 9 and 5 points). We considered the discrepancy in assessments for pairs of conflicting attitudes as a fact of overcoming the "double bind". Total score for all answers was an indicator of the degree of effectiveness of "double binds" implemented in the interaction of teachers with students.

Factor analysis made it possible to identify the following reasons for "double bind" of students: adaptation to actual (but not the declared requirements of a teacher (factor 1); striving to demonstrate his/her personal position (factor 2), ignoring labor-intensive work (factor 3); simplification of information and its search (factor 4); striving to be considered a 
conscientious student (factor 5); striving for scientific comprehension and presentation of information (factor 6). Here are the statements included in factor 4 as having a direct connection with the problem of students' clip way of thinking: "A student should not act creatively while learning, but in accordance with the stereotypes suggested by the teacher" (the average grade, according to scaling data, is 5.9); "When preparing for seminars, it is enough to download the answers from the Internet, although the teacher demands to make notes from original sources" (average grade is 7.7), "Information presented by the student mainly in the form of pictures and illustrations is perceived better than the text one" (average grade is 5.1). Factor 3 can also be considered as associated with clip way of thinking, this factor is formed by two variables: "If you make notes from original sources as you should, you may not have time to prepare for the seminar entirely" (average grade is 6.3); "Teachers do not encourage the student to have questions on the topic of the lesson, since discussion will be time-consuming" (average grade is 7.3).

The results of factorization of "double bind" parameters are presented in Table 1.

Table 1. Factor loads of the parameters of "double bind" of students after varimax rotation.

\begin{tabular}{|l|l|c|c|c|c|c|c|}
\hline \multicolumn{2}{|l|}{$\begin{array}{l}\text { "Double bind" parameters } \\
\text { (original variables) }\end{array}$} & \multicolumn{7}{c|}{ Factors } \\
\cline { 2 - 7 } & $\mathbf{1}$ & $\mathbf{2}$ & $\mathbf{3}$ & $\mathbf{4}$ & $\mathbf{5}$ & $\mathbf{6}$ \\
\hline 1. & Creativity & 0.902 & -0.270 & -0.019 & -0.066 & -0.032 & -0.076 \\
\hline 2. & Personal opinion & -0.263 & 0.469 & 0.178 & -0.006 & 0.581 & 0.536 \\
\hline 3. & Making notes of texts & -0.193 & -0.156 & 0.850 & 0.069 & 0.003 & -0.12 \\
\hline 4. & $\begin{array}{l}\text { Refusal from the usage of a } \\
\text { smartphone in class }\end{array}$ & 0.227 & 0.012 & -0.069 & 0.167 & 0.889 & 0.236 \\
\hline 5. & Text and tabular information & -0.198 & 0.061 & 0.164 & 0.181 & 0.269 & 0.821 \\
\hline 6. & Without text visualization & 0.075 & 0.863 & -0.140 & -0.080 & -0.206 & 0.320 \\
\hline 7. & Scientific presentation & 0.875 & 0.178 & -0.261 & 0.140 & 0.083 & 0.050 \\
\hline 8. & Questions to the teacher & 0.225 & 0.348 & -0.100 & -0.065 & 0.042 & 0.752 \\
\hline 9. & Priority of educational work & 0.633 & -0.133 & 0.221 & 0.114 & 0.595 & -0.052 \\
\hline 10. & Following stereotypes & 0.034 & -0.091 & 0.125 & 0.921 & 0.175 & -0.024 \\
\hline 11. & $\begin{array}{l}\text { Acceptance of the teacher's } \\
\text { opinion }\end{array}$ & 0.700 & -0.166 & -0.116 & -0.481 & -0.047 & 0.045 \\
\hline 12. & Downloading texts & 0.511 & -0.113 & 0.243 & 0.675 & -0.133 & 0.402 \\
\hline 13. & Using a smartphone in class & 0.601 & 0.375 & 0.362 & -0.040 & 0.322 & -.0332 \\
\hline 14. & Pictures and illustrations & -0.328 & -0.125 & -0.271 & 0.623 & 0.539 & 0.113 \\
\hline 15. & Text visualization & 0.062 & -0.959 & 0.005 & 0.077 & -0.130 & 0.023 \\
\hline 16. & $\begin{array}{l}\text { Presentation at the everyday } \\
\text { level }\end{array}$ & 0.762 & 0.486 & -0.107 & 0.276 & 0.156 & 0.131 \\
\hline 17. & Absence of questions & 0.094 & -0.014 & 0.855 & 0.210 & 0.084 & 0.382 \\
\hline 18. & $\begin{array}{l}\text { Priority of extracurricular } \\
\text { activities }\end{array}$ & 0.158 & -0.477 & -0.568 & 0.327 & 0.378 & 0.048 \\
\hline
\end{tabular}

The factor analysis procedure, undertaken in relation to students' rating of statements related to clip way of thinking, revealed the following factors: superficiality of information processing (factor 1), are flexivity (factor 2), simplification, linguistic minimalism (factor 3), efficiency, speed of information processing (factor 4), impulsivity and discontinuity in communication (factor 5), stereotyped thinking (factor 6).

The results of factorization of the parameters of clip way of thinking of students are presented in Table 2 . 
Table 2. Factor loads of students' clip way of thinking parameters after varimax rotation.

\begin{tabular}{|c|c|c|c|c|c|c|c|}
\hline \multirow{2}{*}{\multicolumn{2}{|c|}{$\begin{array}{c}\text { Clip way of thinking parameters } \\
\text { (original variables) }\end{array}$}} & \multicolumn{6}{|c|}{ Factors } \\
\hline & & 1 & 2 & 3 & 4 & 5 & 6 \\
\hline 1. & $\begin{array}{l}\text { Speed of information } \\
\text { processing }\end{array}$ & 0.137 & -0.639 & 0.225 & 0.638 & 0.021 & 0.281 \\
\hline 2. & $\begin{array}{l}\text { Lack of } \\
\text { concentration }\end{array}$ & 0.181 & -0.105 & 0.004 & 0.940 & -0.088 & 0.217 \\
\hline 3. & Linguistic minimalism & -0.014 & -0.050 & 0.858 & -0.015 & 0.098 & -0.275 \\
\hline 4. & $\begin{array}{l}\text { Internet is the main source of } \\
\text { information }\end{array}$ & 0.376 & 0.269 & -0.131 & 0.804 & 0.197 & -0.160 \\
\hline 5. & $\begin{array}{l}\text { Rapid forgetting of } \\
\text { information }\end{array}$ & 0.941 & 0.123 & -0.077 & 0.223 & -0.118 & 0.019 \\
\hline 6. & Areflexivity & 0.799 & -0.086 & 0.343 & 0.063 & 0.039 & 0.198 \\
\hline 7. & $\begin{array}{l}\text { Nervousness and uneasiness } \\
\text { of the gadget user }\end{array}$ & 0.612 & -0.595 & -0.299 & 0.151 & -0.226 & 0.260 \\
\hline 8. & $\begin{array}{l}\text { Difficulties in working with } \\
\text { large amounts of information }\end{array}$ & 0.979 & 0.117 & 0.048 & 0.030 & 0.027 & 0.079 \\
\hline 9. & $\begin{array}{l}\text { Simplification of problem } \\
\text { solving }\end{array}$ & 0.154 & 0.102 & 0.912 & 0.032 & -0.006 & 0.087 \\
\hline 10. & Ignoring of context & 0.273 & 0.721 & 0.321 & 0.194 & 0.281 & -0.037 \\
\hline 11. & $\begin{array}{l}\text { Difficulties in formulating } \\
\text { an opinion }\end{array}$ & 0.125 & 0.710 & -0.409 & -0.159 & 0.253 & 0.265 \\
\hline 12. & Stereotyped thinking & 0.005 & -0363 & -0.219 & 0.452 & -0.331 & 0.668 \\
\hline 13. & $\begin{array}{l}\text { Shallow analysis of } \\
\text { information }\end{array}$ & -0.369 & 0.817 & 0.105 & 0.012 & 0.039 & 0.214 \\
\hline 14. & Weak concentration on ideas & -0.015 & 0.713 & 0.067 & -0.009 & -0.648 & -0.059 \\
\hline 15. & Intellectual laziness & -0.449 & -0.005 & 0.628 & -0.518 & -0.250 & -0.188 \\
\hline 16. & $\begin{array}{l}\text { Devotion to video clips } \\
\text { viewing }\end{array}$ & -0.141 & -0.225 & 0.118 & -.0057 & -0.034 & -0.862 \\
\hline 17. & Usage of "emoticons" & -0.038 & 0.249 & 0.023 & 0.065 & 0.944 & -0.077 \\
\hline 18. & $\begin{array}{l}\text { Impulsiveness } \\
\text { discontinuity } \\
\text { communication }\end{array}$ & -0.689 & 0.133 & 0.431 & -0.345 & 0.396 & -0.067 \\
\hline 19. & Superficial thinking & 0.720 & -0.198 & 0.035 & 0.308 & 0.182 & -0.133 \\
\hline 20. & Quick access to information & -0.596 & 0.205 & 0.492 & -0.126 & -0.026 & -0.085 \\
\hline
\end{tabular}

Here are the statements that got maximum average grades during polling survey: "I can quickly grasp information and swiftly draw conclusions" (average grade is 6.3); "Current level of thinking presupposes linguistic minimalism: information should be formulated clearly and concisely" (6.0); "The consequence of active use of gadgets is the user's nervousness and uneasiness" (5.6); "I, as well as my peers, experience difficulties in perceiving significant amounts of information, reading large works" (6.3); "Any task, you faced with, should be simplified, solution of the problem should be simple, concise, with the minimum use of necessary means" (6.3), "Sometimes I have difficulties when trying to formulate my personal opinion and personal position" (5.0), " The advantage of my generation is quick access to wide range of information "(7.2).

Correlation analysis according to Spearman (two-tailed test) revealed a significant correlation with $\mathrm{P}<0.01(\mathrm{R}=0.467 * * ; \mathrm{N}=54)$ between the intensity of "double bind" of students (total score of each surveyed as to all statements) and the severity of clip way of thinking (also determined by the amount of points for each surveyed). This result provides an opportunity to state the connection between the desire of students to meet the sometimes conflicting expectations and requirements of teachers and their appeal to cognitive style, designated as "clip way of thinking". 


\section{Discussion}

The features of "clip way of thinking" are its are flexivity, fragmentation, nonlinearity, visualization, imaging, a decrease in semantic processing of information, consumer attitude to information, efficiency of refocusing in information flow (Zemlinskaya, Fersman, 2016; Kolobaev, Vorobieva, 2019;Krainiukov, 2019; Krainov, 2019; Polyakov et al.; Prensky, 2012; Rosen, 2007;Semenovskikh, 2016; Shalova, Efremova, 2019 etc.). Some of the controversial prescriptions of "double bind" directly refer to reinforcement of these features of "clip way of thinking". Thus, a student is given the task to write an essay using original sources, instead of not to download from the Internet, but in the end he/she successfully delivers a work taken entirely from the Internet. Sometimes the teacher negatively assesses both a computer presentation, excessively saturated with pictures, and the one in which textual information predominates. On the one hand, necessity to activate the student's oral speech in class is specified, on the other hand, brevity and laconic answers are encouraged. It is suggested to state an idea in a simple and accessible way, but a scientific presentation is rated higher. Then the ban of smartphone usage during class time is followed, but it is tacitly allowed to break this ban. There is a request for creativity and independent point of view of the student, thus the originality of the viewpoint is not encouraged. The student is invited to ask questions on the topic of the lecture, but it is intonationally demonstrated that the time has run out and there is no need to ask questions. Educational activity is declared as being of primary importance for a student, but often preference is given to extracurricular activities performed at the expense of educational process. These conflicting prescriptions can be demonstrated publicly or privately, by one or different teachers. As a result, the student becomes disoriented, he/she experiences state of uncertainty, minimizes educational activity, and uses ready-made information products. In the classroom, the student demonstrates cognitive style, characterized by clip-like perception of educational information. His/her thinking is operative, but shallow, areflexive and fragmented.

We suggested that there was a connection between the degree of manifestation of the conflicting didactic requirements of teachers, creating "double bind" for students, and intensity of implementation in their educational activities of cognitive style, characterized by researchers (Semenovskikh, 2014; Chirkova, 2016, etc.) as "clip way of thinking".

In our study, students were asked to rate on a scale from 0 to 9 points the degree of acceptance of each of the statements of the following pairs of conflicting requirements of teachers: 1) work creatively or according to the proposed templates, 2) express or not express their personal point of view, 3) take notes of scientific original sources or build a presentation on the Internet reviews, 4) use or not smartphone in the classroom, 5) present information in text and tabular form or in the form of pictures and illustrations, 6) support information or not with a visual background, 7) express an idea in complicated scientific or plain (everyday) language, 8) ask the teacher questions or not, 9) give preference to educational or extracurricular activities. Each of the alternatives was built in the form of statements, for example: "The occurrence of questions on the topic of the lesson is encouraged by the teachers", "The occurrence of questions on the topic of the lesson is not encouraged by the teachers, since the discussion will take a lot of time." Suggesting of alternatives was ranked in the course of polling survey: reverse alternatives ( 9 statements) were suggested after all direct ones; total amount of 18 questions were asked.

Furthermore, the students were suggested another questionnaire, in which they expressed the degree of agreement (also from 0 to 9 points) with 20 statements characterizing clip way of thinking. The statements were composed based on the indicators of clip way of thinking described in the literature of the subject (Chirkova, 2016; Zemlinskaya, Fersman, 2016; Kolobaev, Vorobieva, 2019; Semenovskikh, 2014etc.). Here are some examples of statements to be rated: "I don't need extensive concentration on information, thoughtfulness 
and long reflections are the lot of the elderly generation", "I, as well as my peers, experience difficulties in perceiving significant amounts of information, reading large works", "Stereotype and conventionality is a distinctive feature of the younger generation thinking". "To designate emotional states with the help of "emoticons" is the most handy way", "The consequence of active use of gadgets is the user's nervousness and uneasiness". In other statements, a tendency towards quick "grasping" and rapid forgetting of information, linguistic minimalism, priority information sourcing from the Internet, simplification of intellectual tasks, a decrease in reflection regarding perceived information, devotion to video clips, video news, blogs viewing was stated.

Based on the results of each of the two scaling procedures, a factor analysis was carried out (SPSS 17.0 program, principal component analysis, varimax rotation with Kaiser normalization). Correlation analysis (according to Spearman, two-tailed test) was also carried out to determine the presence or absence of a connection between the intensity indicator of "double bind" of students (total score as to 18 questions) and the indicator of manifestation of clip way of thinking (total score as to 20 questions).

The survey involved 54 students of the Department of Psychology and Social Pedagogy of Taganrog State Teachers Training Institute named after A.P. Chekhov (branch) of Rostov State University of Economics (RINH).

\section{Conclusions}

1. In educational activities of students, a situation of "double bind" is often created, when they strive to meet conflicting expectations and requirements of teachers, not daring to express disagreement with these requirements and discuss them. Contradictory requirements of teachers, creating a "double bind", intensify students' appeal to clip way of thinking in educational activities.

2. The following internal reasons that determine the occurance of a situation of "double bind" among students are to be emphasized: adaptation to actual, not declared, requirements of teachers; striving to demonstrate personal position, which sometimes does not coincide with the position of the teacher; ignoring time-consuming work when understanding its necessity; striving to be considered a conscientious student while trying to minimize efforts in academic work.

3. The cognitive style of clip way of thinking, realized, in particular, in a situation of "double bind", may appear in superficiality of information processing, areflexivity, simplification, linguistic minimalism, speed of work with information, sometimes at the expence of quality, stereotyped statements and conclusions.

4. Teachers should avoid conflicting requirements, applicable to students. It is necessary to clearly monitor the fulfillment of the requirements in order to avoid acceptance of conflicting attitudes by students, when they understand sufficiency of the teacher's requirements, but also realize possibility of violation if their non-fulfillment is tacitly allowed.

5. Clarity and unambiguity of instructions and requirements of the teacher, as well as control of compliance with them are important conditions for the manifestation of such qualities of thinking in the educational process as depth, problematicity, consistency, criticality and reflexivity.

\section{References}

1. G. Bateson, Steps to an Ecology of Mind. Collected essays in anthropology, evolution and epistemology (Chandler Pub. Co., San Francisco, 1972) 
2. B.O. Mayer, Electronic journal "Bulletin of the Novosibirsk State Pedagogical University" 3(7), 44-55 (2012) doi: 10.15293/2658-6762

3. M. Shpitzer, Anti-brain: digital technologies and the brain (AST, Moscow, 2008)

4. Yu.D. Babaeva, A.E. Voiskunsky, Psychological Journal 1, 89-100 (1998)

5. T.I. Chirkova, Psychological science and education 1(8), 45-61 (2016) doi: 10.17759/psyedu.2016080105

6. T.E. Zemlinskaya, N.G. Fersman, Humanities and Social Sciences 4(255), 153-160 (2016) doi: 10.58627JHSS.255.18

7. V.K. Kolobaev, K.V. Vorobieva, International Research Journal 9(87), 14-17 (2019) doi: 10.23670/IRJ.2019.87.9.027

8. S.V. Krainiukov, Social psychology and society 4(10), 23-41 (2019) doi: $10.17759 /$ sps.2019100403

9. A.L. Krainov, Izvestiya of Saratov University. New Series. Series: Philosophy. Psychology. Pedagogy 3(19), 262-266 (2019) doi: 10.18500/1819-7671-2019-19-3262-266

10. S.D. Polyakov, L.A. Belozerova, V.V. Vershinina, S.V. Danilov, N.S. Krivtsova, Moscow University Bulletin. Series 14: Psychology 4, 126-143 (2019) doi: 10.11621/vsp.2019.04.126

11. V. Prensky, From digital natives to digital wisdom: Hopeful essays for $21^{\text {st }}$ century learning (Corwin Press, Thousand Oaks, California, 2012)

12. L.D. Rosen, Me, MySpace, and I: Parenting the Net Generation (St Martin`s Publishing Group, N.Y., 2007)

13. T.V. Semenovskikh, Internet journal "Naukovedenie" 5(24), 1-10 (2014)

14. S. Shalova, O. Efremova, Trends in the Development of Psycho-Pedagogical Education in the Conditions of Transitional Society (ICTDPP-2019), 08036 (EDP Sciences, Les Ulis, 2019) doi:10.1051/shsconf/20197008036 